\title{
Loss of Consciousness Following Mismanagement of Pisa Like Posture
}

\author{
Reza Bidaki ${ }^{1,2 *}$ and Maryam Akrami ${ }^{1}$ \\ ${ }^{1}$ Department of Psychiatry, Research Center of Addiction and Behavioral Sciences, Shahid Sadoughi University of \\ Medical Sciences, Yazd, Iran \\ ${ }^{2}$ Yazd Diabetes Research Center, Shahid Sadoughi University of Medical Sciences, Yazd, Iran
}

*Corresponding author: Reza Bidaki, Department of Psychiatry, Research Center of Addiction and Behavioral Sciences, Shahid Sadoughi University of Medical Sciences, Yazd, Iran, Tel: +98 3532633555; Fax: +98 3532633555; E-mail: Reza.Bidaki111@gmail.com

Citation: Bidaki R, Akrami M (2016) Loss of Consciousness Following Mismanagement of Pisa Like Posture. Gavin J Addict Res Ther 2016: 11-12.

Received: 22 May, 2016; Accepted: 30 May, 2016; Published: 13 June, 2016

\section{Dear Editor,}

Drug induce dystonia isn't uncommon follow psychopharmacotherapy especially high potent traditional anti-psychotics with high dose or without anticholinergic agents. Usually, this important side effect is diagnosed by physicians. The misdiagnosed of these subjects aren't common. We intend introduce a female patient with Obsessive- Compulsive Disorder and Bipolar Disorder type I that she get a uncommon posture in stature like as trunk deviation or pisa like posture. But with diagnosis of acute dystonia, she received anticholinergic and underwent loss of consciousness rapidly and referred to ICU.

The sustained unsuitable posture or mascular spasm can occur follow anti-psychotic agents within one week of starting, rapidly elevation of dosage or loss of anticholinergic medication [1].

Also, acute dystonia can occur follow anticonvulsions, tricyclic antidepressants. It happen slow, sustain, involuntary. It's manifestations are as tongue protrusion, opisthotonus, oculogyric crisis, torticollis and laryngeal spasm, which may cause an emergency [2].

We hadn't sufficient evidence for antipsychotic induce dystonia about this patient.

The 31 year-old married woman, from the West of Iran was been hospitalized because of Obsessive-Compulsive Disorder with suitable insight, clean- contamination type. She was not only severe obsessive but also high aggressive with history of cigarette smoking 1 pack/day. The drugs include:

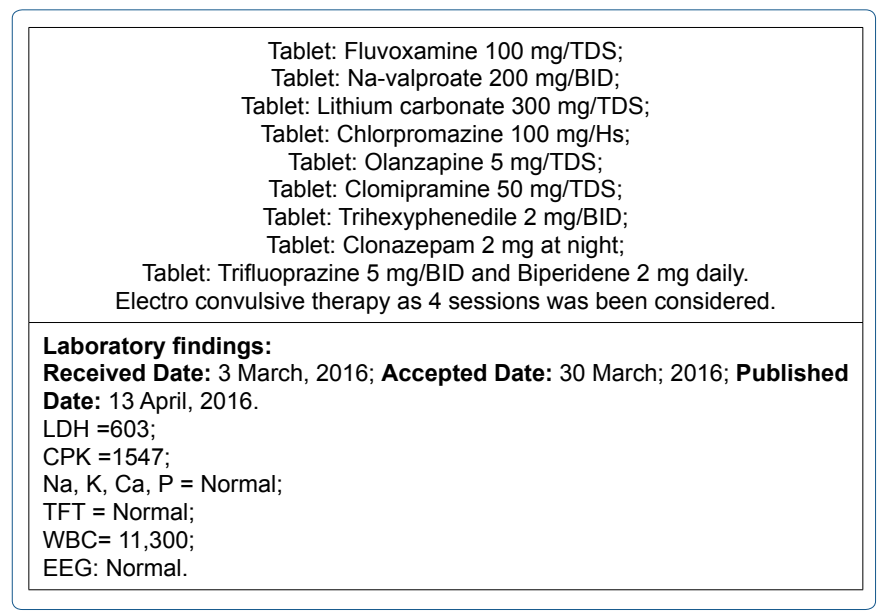

She consumed the detergents daily as disinhibited. She used 4 soap, 2 shampoo and 1 toothpaste. She was very agitated, irritable, aggressive and non-cooperative in psychiatry ward. Therefore, his physicians prescribed Amp. Haloperidol $5 \mathrm{mg}$ and Amp. Biperidene $5 \mathrm{mg} \mathrm{IM} / \mathrm{PRN}$. In $6^{\text {th }}$ day of admission, she complained of low back pain and tilted/curved on right hemi side. Her position was like a type of dystonia and scoliosis. The patient had illness behavior and attention seeking. She hadn't torticollis, tongue protrusion, and respiratory failure. Therefore, the factitious disorder and malingering were considered. Of course, it was doubted dystonia because of drugs. Therefore she was injected Amp. Biperidene $5 \mathrm{mg}$ twice in 24 hours. The two next day, she had a loss of consciousness, $\mathrm{PR}=70 / \mathrm{Min}, \mathrm{GCS}=4 / 15$ and referred to ICU. The supportive treatments were considered in ICU. After 4 days, she discharged of ICU and admitted in psychiatry ward again. The obsession and irritability were declined significantly. 
The familial history was positive about OCD for 4 sisters and mood disorder for all brothers.

The lateral trunk flexion during sitting or standing is named Pisa syndrome [3] the sign of pisa syndrome included: (a) presence of persistent trunk dystonia; (b) lateral flexion and mildly backward axial rotation of the trunk with absence of other dystonic region; (c) history of psychotropic drugs preceding or concurrent with the onset of dystonia; (d) absence of known causes of secondary dystonia, and (e) absence of dystonia in family history [4]. Pervious study reported that this syndrome induced with neuroleptic medication such as haloperidol and methylperone $[5,6]$. Its risk factors are include: Female gender (9.3\% in women vs $6.4 \%$ in men) [7], elderly, and general medical conditions and long last use of anti-psychotics [4].

Our patient was a young female that had pisa like posture but this symptom was transient and reversible.

Because of multiple drugs, we really discriminate which of drugs are cause of this phenomenon. Perhaps interactions among drugs are etiology of it.

It is need for all physicians that consider the minimum dosage and the least number of drug prescription. Also, consider extra pyramidal syndromes even by uncommon drug for this side effect.

\section{Keywords}

Acute dystonia; Anticholinergic; Obsessive-compulsive disorder; Pisa

\section{References}

1. American Psychiatric Association (2013) Diagnostic and statistical manual of mental disorders. American Psychiatric Association Publishing, Arlington, USA.

2. Munhoz RP, Moscovich M, Araujo PD, Teive HA (2012) Movement disorders emergencies: a review. Arq Neuropsiquiatr 70: 453-461.

3. Benatru I, Vaugoyeau M, Azulay JP (2008) Postural disorders in Parkinson's disease. Neurophysiol Clin 38: 459-465.

4. Harada K, Saito T (2006) Pisa syndrome $\square$ like peculiar posture occurred while running was successfully improved with risperidone. Psychiatry Clin Neurosci 60: 771-772.

5. Yokochi F (2006) Lateral flexion in Parkinson's disease and Pisa syndrome. J Neurol 253: 17-20.

6. Suzuki T, Matsuzaka H (2002) Drug-induced Pisa syndrome (pleurothotonus). CNS drugs 16: 165-174.

7. Stubner S, Padberg F, Grohmann R, Hampel H, Hollweg M, et al. (2000) Pisa syndrome (pleurothotonus): report of a multicenter drug safety surveillance project. J Clin Psychiatry 61: 478-574. 